\title{
Procost - Towards a powerful early stage cost estimating tool
}

Link to publication record in Manchester Research Explorer

\section{Citation for published version (APA):}

Soutos, M., \& Lowe, D. J. (2005). Procost - Towards a powerful early stage cost estimating tool. In L. Soibelman, \& F. Pena-Mora (Eds.), Proceedings of the 2005 ASCE International Conference on Computing in Civil

Engineering/Proc. ASCE Int. Conf. Comput. Civil Eng. (pp. 1503-1514). American Society of Civil Engineers.

\section{Published in:}

Proceedings of the 2005 ASCE International Conference on Computing in Civil Engineering|Proc. ASCE Int. Conf. Comput. Civil Eng.

\section{Citing this paper}

Please note that where the full-text provided on Manchester Research Explorer is the Author Accepted Manuscript or Proof version this may differ from the final Published version. If citing, it is advised that you check and use the publisher's definitive version.

\section{General rights}

Copyright and moral rights for the publications made accessible in the Research Explorer are retained by the authors and/or other copyright owners and it is a condition of accessing publications that users recognise and abide by the legal requirements associated with these rights.

\section{Takedown policy}

If you believe that this document breaches copyright please refer to the University of Manchester's Takedown Procedures [http://man.ac.uk/04Y6Bo] or contact uml.scholarlycommunications@manchester.ac.uk providing relevant details, so we can investigate your claim.

\section{OPEN ACCESS}




\section{MANCHESTER}

The University of Manchester

Manchester Business School

This is the author's version of a work that was submitted/accepted for publication in the following source:

Soutos, M and Lowe, D J (2005) ProCost - Towards a powerful early stage cost estimating tool. In Proceedings of the ASCE International Conference on Computing in Civil Engineering, Cancun, Mexico, 12-15 July. Edited by L Soibelman and F Pena-Mora, ISBN 0-7844-0794-0, \#8878 12 pages, eScholarID: 61109

This file was downloaded from: https://www.escholar.manchester.ac.uk

\section{(C) Copyright 2005 ASCE}

Reproduced in accordance with the copyright policy of the publisher. Notice: Changes introduced as a result of publishing processes such as copy-editing and formatting may not be reflected in this document. For a definitive version of this work, please refer to the published source. 


\title{
PROCOST - TOWARDS A POWERFUL EARLY STAGE COST ESTIMATING TOOL
}

\author{
Michail Soutos $^{1}$ and David J. Lowe ${ }^{2}$
}

\begin{abstract}
On-going research at UMIST commenced in 1997 has resulted in the production of ProCost, an early stage building cost modelling tool. The software is based on Artificial Neural Network technology to produce single figure estimates of the total building cost.
\end{abstract}

Recent research has however indicated that cost estimators cannot nowadays rely on single figure cost estimating techniques (Soutos \& Lowe, 2003 and Soutos \& Lowe, 2004). This initiated the next stage of the research, which involved the investigation of subdividing the single figure cost output into a cost for each building element.

In order to proceed, a large database of 360 buildings with developed elemental cost breakdowns was formulated with the aid of Building Cost Information Service (BCIS). This database was used to investigate the way that a series of building characteristics affect the cost of building elements. In order to model these relationships, linear regression analysis was used. The results of this method are discussed in this paper. Artificial Neural Networks, are then proposed as an additional way of modelling the data, and their advantages over regression analysis are considered. This paper presents the results of an extensive piece of research with respect to ProCost and discusses its evolution into a powerful cost estimating package.

\section{KEY WORDS}

Cost estimating, cost modelling, elemental estimating, regression analysis, artificial neural networks

\section{INTRODUCTION}

Cost estimating is crucial to construction contract tendering, providing a basis for establishing the likely cost of resource elements of the tender price for construction work (Akintoye, 2000). A cost estimate can vary in detail and accuracy depending on the stage of the project at the time of the estimate. The estimates under consideration in the current paper are the ones targeted at the initial stages of the project. According to Seeley (1996) the primary function of feasibility or preliminary estimating is to produce a forecast of the probable cost of a future project, before the building has been designed in detail and contract particulars are prepared. Several researchers have previously commented on the importance of such estimates. Smith (1995), observes that the first estimate that is published for review has a particularly crucial role to play because it is the basis for the release of funds for further studies or estimates, and because it becomes the marker against which subsequent estimates are compared. Moreover, early estimates are important because of the need to know, for the purposes of economic appraisal, the capital cost of the

\footnotetext{
${ }^{1} \mathrm{PhD}$ candidate in Cost Estimating \& Modelling, School of Mechanical, Aerospace and Civil Engineering The University of Manchester, P.O. Box 88, Manchester, M60 1QD, UK. Phone +44 (0) 1612005974 , m.soutos@postgrad.umist.ac.uk.

${ }^{2}$ Senior Lecturer, School of Mechanical, Aerospace and Civil Engineering, The University of Manchester, P.O. Box 88, Manchester, M60 1QD, UK. Phone +44 (0) 161200 4643, david.lowe@umist.ac.uk
} 
project. Trost and Oberlender (2003) seem to agree with these ideas; they consider that early estimates are critical to the initial decision making process for the construction of capital projects. Early estimates, even when grossly inaccurate, often become the basis upon which all future estimates are judged (with future estimates corrected to be consistent with early estimates).

Nevertheless, studies by Ellis \& Turner (1986) and Proctor, Bowen et. al. (1993), have indicated that clients are very often dissatisfied with the initial cost advise that they were provided with by their construction professionals. In trying to aid this area, and by the late advancement of technology, the concept of cost modelling appeared. Ferry and Brandon (1991) define cost modelling as a symbolic representation of a system, expressing the content of that system in terms of the factors, which influence its cost. The main idea of cost modelling is to simulate a current or future situation in such a way that the solutions posed in the simulation will generate results, which may be analysed and used in the decision-making process of design (Ashworth, 1986). It is a genuine belief and hope that cost models would be able to improve the situation in the construction industry and offer consultancies and contractors the opportunity to provide improved cost advice to clients. This seems to be a common belief amongst quantity surveyors and cost consultants in the UK (Fortune and Lees,1996). Researching the reliability and value of the new modelling methods in comparison with the traditional estimating techniques, Fortune and Lees (1996) found that the new models were considered to be more valuable than the single rate traditional methods. This would indicate that there is potential for new models at the very early stage of project planning; the stage where the model under discussion (ProCost) is aimed at by providing an accurate and powerful estimating tool for today's cost consultant.

\section{MODELLING TECHNIQUES}

There are various modeling techniques available to the estimator today: Others traditional and others more up to date, which utilize the latest advancement in science and technology. In an effort to identify and classify these techniques, Fortune and Lees (1996) came up with the following categories:

- Traditional (Judgment, functional unit, cost per $\mathrm{m}^{2}$, principal item, interpolation, elemental analysis, significant items, approximate quantities, detailed quantities)

- Statistical (regression analysis, time series models, casual cost models)

- Knowledge based (ELSIE, other knowledge based )

- Life cycle costing (Net Present Value, Payback method, discounted cash flow)

- Resource/process (Resource based, process based, construction cost sim)

- Risk analysis (Monte Carlo simulation, Other risk analysis)

- Value rated (Value management, other value related)

A quick description of the techniques relevant to this paper follows.

\section{REGRESSION ANALYSIS}

Regression analysis is a statistical technique. Its basic concept is that the value of a dependent variable can be found using a mathematical formula, which contains a variety of other independent variables the values of which are known or can be found. In the case of regression analysis models for cost estimating, the dependent variable would normally be the cost of the building and the independent variables are those factors that affect the price of the building such as the gross floor area, the number of storeys, plan/shape ratio etc.

The linear regression equation usually takes the form: 
$\mathrm{Y}=\mathrm{A}+\mathrm{B}_{1} \mathrm{X}_{1}+\mathrm{B}_{2} \mathrm{X}_{2}+\ldots+\mathrm{B}_{\mathrm{n}} \mathrm{X}_{\mathrm{n}}$

$\mathrm{Y}$ is the dependent variable (cost) and $\mathrm{X}_{1}, \mathrm{X}_{2}, \mathrm{X}_{\mathrm{n}}$ are the independent variables or measures on some characteristics that affect $\mathrm{Y}$ (gross floor area, number of storeys, plan/shape ratio, etc). A, $\mathrm{B}_{1}, \mathrm{~B}_{2}, \mathrm{~B}_{\mathrm{n}}$ are the values of the independent variables. This technique is used in those situations where the relationship between the variables is not unique, in the sense that a particular value of one variable always corresponds to the same value of other variables (Ashworth, 1981). Different types of regression models can be developed, they include a simple linear, a multiple linear or a non-linear polynomial regression (Makridakis et. al., 1983). The method selected in this study is multiple linear regression, as more than one independent variables are involved.

\section{ARTIFICIAL NEURAL NETWORKS (ANN)}

A Neural Network is a type of information processing system whose architecture is inspired by the structure of human biological systems (Caudill and Butler 1990). This means that it is built following the same structure that the human brain has, so that it functions in the same or similar way. There are a series of different neural networks definitions. According to Boussabaine (1996), ANNs are an information processing technology that simulate the human brain and the nervous system. Like the human brain, they learn from experience, generalize from previous examples to new ones and abstract essential characteristics from inputs containing relevant data. It should be noted however that Neural Networks are much less complex than their biologic counterparts. For this reason, and to distinguish them from these biological counterparts they are usually referred to as Artificial Neural Networks. The learning ability of neural networks gives an advantage in solving complex problems whose analytic or numerical solutions are hard to obtain (Rafiq et. Al., 2001).

\section{DEVELOPMENT OF PROCOST}

In 1997 a large research project commenced at UMIST with the aim of identifying the way the different procurement routes affect the final cost of a project. It was soon however recognized that the procurement routes could not be isolated from all the other cost significant variables. As a result the research changed scope into producing a cost-estimating tool that could be used during the early design stages of a project.

The work was carried out in two stages (Emsley et. al., 2002).

- The first stage included an initial pilot study where potentially cost significant variables were identified, the availability of data investigated and strategies for data collection were established. In addition appropriate modeling strategies were examined and preliminary testing of these methods was carried out using relatively small number of data sets.

- A full-scale study was made using data from nearly 300 projects.

The first step was to identify the potentially cost significant variables. This was achieved through a thorough literature review as well as via a series of meetings and discussion sessions with the team's industrial collaborators (see acknowledgements). The result was the identification of the variables illustrated in Table 1. These variables were further categorized in project strategic, site related, design related \& building definition, structure, finishes, mechanical, electrical, protective and special installations. 
Table 1: The identified cost significant variables

\author{
Project Strategic: \\ Contract form, contract type, duration, procurement, purpose, tender strategy, LAD
}

\title{
Site Related:
}

Site access, topography, location type, site nature

\section{Design related \& Building definition:}

Envelope, building function, GIFA, height of building, No of storeys above ground, No of storeys below ground, quality, shape complexity, structural units, wall to floor ratio

\section{Structure:}

Substructure, piling, frame, upper floors, roof construction, roof profile, roof finishes, stairs, external walls, windows, external doors, roller shutter doors, internal walls/partitions, internal doors

\section{Finishes:}

Internal wall finishes, floor finishes, ceiling finishes

Mechanical Installations:

Air condition, Lifts, total mechanical installations

\section{Electrical installations}

Protective installations

Special installations

The data collection program resulted in the compilation of 288 full data sets. These were obtained from the industrial collaborators as well as other quantity surveying and project management practices that were willing to provide information. Data was also generated from the online service of BCIS (building cost information service).

Regression analysis and ANN techniques were used to model the data, with the ANN model proving more accurate than regression. The reason for this is that neural networks offer the ability to capture the non-linearity that inevitably exists between the variables. Following the training and testing of the neural network, the final model was ready.

\section{THE NEED FOR EVOLUTION}

The result was the development of cost estimating software that could be used to provide single figure cost estimates for any kind of proposed building at the very early stages of the project. How useful was this final package? Was it enough to cover the needs of the practicing quantity surveyor, consultant or cost estimator? In order to test the model and find the answers to these questions a twofold survey was initiated. This included:

1. Consultation with the industrial collaborators.

2. A nationwide questionnaire survey.

The collaborators did already have the software, and were using it in conjunction with their own estimating techniques. The fact that their advice is based on practical involvement with the software makes it of major value. One of the main outcomes of the consultation with them was the need of an elemental estimating tool within the software. This, according to them would provide the user with greater control of the pricing of the building as well as giving the opportunity for a comparison with the bill of quantities once one is prepared. This gave the research team an initial indication, but although it was a common request amongst all the collaborators, it was not enough to assume that this is the position of the wider quantity surveying 
profession. For this reason it was decided to proceed to the second stage of this investigation, which included a nationwide survey in the form of a posted questionnaire. 500 firms were contacted across England, Scotland, Wales and Northern Ireland. The response rate achieved was $40 \%$. The questionnaire examined two areas. The suitability of a single figure price estimating tool to the needs of the estimator and the common practice of elemental estimating currently in use. This way, if the results of the first part of the questionnaire confirmed that a single figure price estimating piece of software is of limited use to the estimator, the elemental breakdown formats used in practice would be known to be used as a basis to center the proposed elemental tool on.

Eventually the case that the collaborators brought up seemed to be confirmed as a general belief of the quantity surveying profession. The detailed results of the questionnaire have been published elsewhere (Soutos \& Lowe, 2003 and Soutos \& Lowe, 2004) but the general outcome of interest to the current paper was that the incorporation of an elemental estimating tool into the current form of ProCost is vital. As an indication, about $70 \%$ of the respondents would not use a single figure estimating software at the moment, $85 \%$ of which would though be encouraged to use it if an elemental estimating tool was added. The views of the industrial collaborators in combination with the results of the questionnaire survey indicated that there is a practical need for the evolution of the software in its current form into an integrated elemental cost-estimating tool.

\section{PROGRESSING TO THE NEXT STAGE - THE STUDY FORMAT SELECTION}

Elemental breakdown of costs: How can a building be broken down in separate elements that can be priced as a unit? In what detail should the elemental breakdown be implemented? Are there any standard methods and which ones of them are most commonly used in practice? These were some of the questions that the research team were concerned with during the beginning of this third stage of the research program. As mentioned previously, part of the questionnaire that was circulated nationally was designed to answer these questions. These answers were then discussed and analyzed with the industrial collaborators and their views were considered. The final result is given in table 2 .

Table 2: The elemental format considered

\begin{tabular}{|l|}
\hline 1 Substructure \\
\hline 2 Superstructure \\
2A Frame \\
2B Upper Floors \\
2C Roof \\
2D Stairs \\
2E External Walls \\
2F Windows \& External Doors \\
2G Internal Walls \& Partitions \\
2H Internal Doors \\
\hline 3 Finishes \\
3A Wall Finishes \\
3B Floor Finishes \\
3C Ceiling Finishes \\
\hline 5 Services \\
\hline 7 Preliminaries \\
\hline 8 Contingencies \\
\hline
\end{tabular}


This table illustrates the final elemental analysis format with the elements (in bold) and subelements (in normal font) in the form that will be incorporated within ProCost. The writers named this the reduced detailed level of SFCA. SFCA - standard form of cost analysis - is the standard format introduced by the Royal Institute of Chartered Surveyors (RICS) that the majority of the practitioners in the UK use (75\% of the questionnaire respondents). The SFCA is separated in two levels of detail. The top level consisted of elements and the detailed level consisted of subelements. What is illustrated in table 2 is what is called the "reduced" detailed level, since it appears from the "full" detailed level once some elements and sub-elements are removed (the reason for the abnormal numbering of the elements in the table). The full detailed level of the SFCA includes number 4 - fittings and furnishings, fifteen services sub-elements and number 6 external works. The reason that fittings and external works were not included in the model is that ProCost in its current form does not consider them. The services sub-elements where excluded as they can vary extremely depending on the building type and would therefore be very hard to model.

\section{DATA COLLECTION}

The data needed were past projects with known descriptive characteristics and developed cost analyses. The source used was the online service of the BCIS (Building Cost Information Service). The study was directed to three building types: Residential buildings, office developments and industrial buildings. 120 projects of each category were identified comprising a large database of 360 buildings in total. This is one of the biggest databases for such purposes that can be identified in literature. Elhag and Boussabaine (1999), used 36 projects, while Gunaydin and Dogan (2004), used only 30. It is therefore anticipated that a more integrated, sophisticated model can be produced. As mentioned previously it was decided that the modeling techniques to be followed would be multivariate linear regression and artificial neural networks. The two results could then be compared and the most efficient model chosen. At the time that this paper is written the research is still in development and therefore the current paper will be concerned with the regression analysis of the 120 offices projects.

\section{DATABASE FORMULATION}

For the purposes of regression analysis two databases were developed. One containing the independent and the other the dependent variables. For the case concerned the independent are the cost significant variables illustrated in Table 1, while the dependent variables are the percentage costs of the elements and sub-elements of Table 2. A long process followed, identifying the nature of the cost significant variables for each one of the 120 buildings. All these characteristics were then coded numerically in order to be identifiable by the statistical analysis software. The method of coding has been described in detail in previous publications (Emsley et. al., 2002, Harding et. al., 1999). As regards the second database the percentage costs of each element were derived from BCIS online. The costs of preliminaries and contingencies elements were reduced to cater for the exclusion of fittings and external works.

\section{THE ANALYSIS}

The software used for the analysis was SPSS for Windows, version 11.0.0. Out of the 120 projects 110 excluded LAD, 54 envelope and 35 wall to floor ratio. The lack of this information could cause faults in the models and therefore it was decided that the LAD would not be considered at all, while two regressions would be carried out, one including the envelope and wall to floor ratio predictors and the other excluding them. In addition to this, one forward and one 
backward regression analysis would be run. As a result a total of four regression methods were carried out for each one of the seventeen dependent variables (Table 2). A series of regression models was produced for each one of these variables. These

2 were studied carefully and the model that produced the highest adjusted $\mathrm{R}$ were selected.

The characteristics of each one of the seventeen models are shown in Table 3.

Table 3: The characteristics of the best model selected for each element

\begin{tabular}{|l|c|c|c|c|}
\hline Model & R & R Square & $\begin{array}{c}\text { Adjusted R } \\
\text { Square }\end{array}$ & $\begin{array}{c}\text { Std. Error of the } \\
\text { Estimate }\end{array}$ \\
\hline Substructure & .893 & .797 & .561 & 2.50872 \\
\hline Superstructure & .941 & .885 & .779 & 4.11891 \\
\hline Frame & .982 & .964 & .901 & 1.03914 \\
\hline Upper floors & .957 & .916 & .802 & .88312 \\
\hline Roof & .934 & .872 & .753 & 2.66323 \\
\hline Stairs & .969 & .940 & .826 & .51529 \\
\hline External Walls & .922 & .850 & .689 & 2.89299 \\
\hline Windows \& external doors & .904 & .818 & .621 & 2.21282 \\
\hline Internal walls \& partitions & .977 & .954 & .900 & .52393 \\
\hline Internal doors & .941 & .885 & .771 & .80762 \\
\hline Finishes & .889 & .790 & .526 & 2.18585 \\
\hline Wall finishes & .921 & .849 & .685 & .82024 \\
\hline Floor finishes & .939 & .881 & .657 & 1.37193 \\
\hline Ceiling finishes & .917 & .842 & .683 & .51622 \\
\hline Services & .922 & .850 & .710 & 4.59102 \\
\hline Preliminaries & .860 & .740 & .625 & 2.90183 \\
\hline Contingencies & .684 & .468 & .291 & 9.95757 \\
\hline
\end{tabular}

The value of $R$ demonstrates the percentage of the cases of the element cost that can be explained by the variation of the attributes included in the regression equation and therefore is a measure of the efficiency of the model. It appears from the table that some models would be more efficient than others. The Frame model for example is expected to produce accurate outcomes, while the contingencies model is much less likely to.

\section{THE RESULTS}

Once the regression equations had been formulated they were used to predict the percentage costs for each one of the elements for the 120 buildings of the existing database. These results were then compared with the actual building costs and their variance examined. The outcomes of this comparison are summarized in Table 4 below. 
Table 4: Regression analysis results summary

\begin{tabular}{|c|c|c|c|c|}
\hline Ref. & Element Sub-element & $\begin{array}{c}\text { Variance of } \\
\text { means } \\
\text { (between actual } \\
\text { \& predicted } \\
\text { value) }(\%)\end{array}$ & $\begin{array}{c}\text { MAPE (out } \\
\text { of } 95 \% \text { most } \\
\text { significant } \\
\text { projects) (\%) }\end{array}$ & $\begin{array}{l}\text { Percentage of } \\
\text { analyzed projects } \\
\text { producing } \\
\text { variance up to } \\
25 \%(\%)\end{array}$ \\
\hline 1 & SUBSTRUCTURE & 36.4 & 75.9 & 42 \\
\hline 2 & SUPERSTRUCTURE & 4.7 & 9.2 & 88 \\
\hline $2 \mathrm{~A}$ & Frame & 11.3 & 12.6 & 74 \\
\hline $2 \mathrm{~B}$ & Upper Floors & 14.3 & 60.9 & 48 \\
\hline $2 \mathrm{C}$ & Roof & 16.8 & 40.5 & 40 \\
\hline $2 \mathrm{D}$ & Stairs & 60.5 & 193.9 & 1 \\
\hline $2 \mathrm{E}$ & External walls & 11.6 & 19.3 & 70 \\
\hline $2 \mathrm{~F}$ & $\begin{array}{l}\text { Windows \& external } \\
\text { doors }\end{array}$ & 9.2 & 28.4 & 71 \\
\hline $2 \mathrm{G}$ & $\begin{array}{l}\text { Internal walls \& } \\
\text { partitions }\end{array}$ & 53.2 & 97.9 & 8 \\
\hline $2 \mathrm{H}$ & Internal doors & 0.3 & 56.7 & 43 \\
\hline 3 & FINISHES & 0.06 & 13.3 & 78 \\
\hline $3 \mathrm{~A}$ & Wall finishes & 22.2 & 62.7 & 50 \\
\hline $3 \mathrm{~B}$ & Floor finishes & 8.2 & 68.2 & 26 \\
\hline $3 \mathrm{C}$ & Ceiling finishes & 9.9 & 21.6 & 72 \\
\hline 5 & SERVICES & 2.4 & 9.9 & 91 \\
\hline 7 & PRELIMINARIES & 81.3 & 319.6 & 6 \\
\hline 8 & CONTINGENCIES & 43.2 & 260.4 & 9 \\
\hline
\end{tabular}

As it appears from this table, three were the major measures of accuracy used. First of all the variance of means between the predicted and the actual values. This measure gives an indication but cannot provide reliable information regarding the absolute accuracy of the models. The means of the prediction and the actual value might be close simply by chance, without necessarily reflecting the general variance for all the projects. In order to measure this, the MAPE (mean absolute percentage error) is used. This is produced by the equation

\section{Predicted Values Mean - Actual Values Mean}

\section{Actual Values Mean}

$$
\times 100 \%
$$

and therefore provides summary information for the absolute mean of all the 120 variances. Finally the last measure used is based on Ashworth's (1996) findings, according to which the actual (as opposed to perceived) accuracy of estimating at the initial stages is $\pm 25 \%$. Looking at Table 4 the results vary considerably from very accurate models to very poor.

The best model appears to be the superstructure model with a MAPE of $9.2 \%$, and $88 \%$ of the projects (106 of the 120) producing a variance up to $25 \%$. The services model has a slightly bigger MAPE (9.9\%), but $91 \%$ of the projects analyzed produce a variance up to $25 \%$. The frame and finishes are amongst the very accurate predictive models too, followed by the external walls and ceiling finishes models. The MAPEs produced by the rest of the models are too great to confidently rely on them for estimating purposes. 


\section{THE WAY FORWARD - ARTIFICIAL NEURAL NETWORKS}

As it appears from the above discussion, regression analysis provides some very accurate models, but its overall performance for the entire elemental cost estimating system cannot be acknowledged as satisfying. Based on past experience and an extended literature review it is the writers' belief that artificial neural networks could prove to be a better modeling technique for the particular type of data.

\section{RAISING THE CASE}

According to Rafiq et. al (2001), the learning ability of neural networks gives an advantage in solving complex problems whose analytic or numerical solutions are hard to obtain. Early stage cost estimation can be regarded as one of these problems especially after the results obtained in this study from regression analysis - an analytic numerical method. Boussabaine (1996), adds that adaptivity allows the neural network to perform well even when the environment or the system being modeled varies with time, which is exactly the case for cost estimating. Shtub and Versano (1999), found in their study comparing ANN and regression that neural networks outperform linear regression analysis for cost estimation. In a similar study, Elhag and Boussabaine (1999) did not find significant difference in the average accuracy results obtained by the two techniques, although ANN proved slightly more accurate. As previously mentioned however, neural networks, unlike linear regression, can model interdependencies between input data, which will inevitably occur when considering cost significant variables (Emsley et. al., 2002). Also ANN can deal better with non-linear relationships; and if there is indeed a relationship between the dependent and independent variables of our study the majority of the results provided (see Table 4) prove that it is not linear. ProCost requires from the user to describe the building under concern using 44 cost significant variables (see Table 1). Depending on how preliminary the stage of the estimation is, it is possible that not all of these variables will be known to the estimator at the time. This can result to incomplete data sets. It is this fact that raises the final case towards the use of ANN, since they have the ability to handle incomplete data sets more effectively than regression (Lowe et. al., 1999).

\section{METHODOLOGY}

The data to train the neural network are already obtained: 360 projects with detailed developed cost analyses. These data will be divided into two categories, one for the training and one for the testing phase of the network. One neural network model will be developed for each one of the seventeen elements identified (see Table 2). Each one of these neural networks will have an input layer of 44 processing elements (neurons) corresponding to the 44 variables that were found to affect the cost of each element (see Table 1). The number of the hidden layers will be identified after several trials. The back-propagation algorithm will most probably be used. Supervised training will be used, presenting the ANN with the target cost for each one of the projects inputted. After the networks have been trained, they will be tested using the remainder of the data in order to specify their general performance and their predicting capabilities.

\section{CONCLUSIONS}

This paper has reviewed research carried out at UMIST with respect to ProCost an early stage cost estimating package. After a general overview of the modeling techniques concerned, some background information on the software was provided. Its evolution from its inception stage (a program to model the cost of different procurement routes) to a fully integrated early stage estimating software with an elemental cost analysis tool was discussed. The methodology of 
finding the cost significant variables and collecting the required data was discussed and the results of the regression analysis carried out on part of the data were given. The fact that regression analysis did not give as accurate results as anticipated was based on the hypothesis that a relationship between the predictors and the dependent variables exists but is not linear. With this as the main reason and based on a series of past publications recommending artificial neural networks as a more suitable technique for the specific attempt, the paper ended by proposing further modeling using the ANN method.

Elhag and Boussabaine (1999) concluded that: "The estimation models were developed using a sample of 36 office buildings. However it is recognized that neural network is data intensive technique, therefore to enhance the reliability of these models, it is recommended to exploit more projects for future development". Gunaydin and Dogan (2004), in their paper on neural networks in estimating also concluded: "ANN learn from examples and so the performance of a neural network model of cost estimation strongly depends on the quality and the quantity of examples. The more examples there are, the less the prediction error is. Thus, to study modeling and prediction methods and construct an accurate prediction model of building costs, there is a need for reliable, high quality, full scale cost data of buildings of various types and conditions". The current research is a response to the call for a greater amount of quality data. The existing database in combination with the previously proven power of artificial neural networks to effectively model complex non-linear relationships, is anticipated to prove as the perfect method for the production of a most powerful integrated cost estimating tool.

\section{ACKNOWLEDGMENTS}

The authors would like to acknowledge the contribution of the ProCost industrial collaborators: EC-Harris, Symonds and Tweeds for their contribution during the study and invaluable comments during the continuous testing of the model. Also, BCIS for their contribution during the study and the data provided. Finally all the quantity surveying, cost consulting and project management practices that replied to the questionnaire survey.

\section{REFERENCES}

Akintoye A. (2000). Analysis of factors influencing project cost estimating practice. Construction Management and Economics. 18, 77-89

Ashworth (1981) Cost modeling for the construction industry. Quantity Surveyor, vol.37, July 1981

Ashworth A. (1986). Cost models - Their history development and appraisal, Technical Information Service No. 64, CIOB

Ashworth A. (1996). Pre-contract studies: Development economics, tendering and estimating. Addison Wesley Longman Limited, Harlow, Essex

Boussabaine A.H. (1996). The use of artificial neural networks in construction management: a review. Construction Management and Economics, 14, 427-436

Caudill M. and Butler C. (1990), Naturally intelligent systems, MIT Press, Mass

Ellis C., Turner A. (1986). Procurement problems, Chartered quantity surveyor, April, p.11

Emsley M.W., Lowe D.J., Duff A. R., Harding A., Hickson A. (2002). Data modeling and the application of a neural network approach to the prediction of total construction costs. Construction Management and Economics, 20, 465-472

Elhag T., Boussabaine A. (1999). Tender price estimation: neural networks vs. regression analysis, Proceedings of the RICS Construction and building research conference, University of Salford, pp 114-23

Ferry D.J. and Brandon P.S. (1991) $6^{\text {th }}$ ed. Cost Planning of Buildings, BSP Professional Books, 


\section{Oxford, UK}

Fortune C. and Lees M. (1996). The relative performance of new and traditional cost models in strategic advice for clients. RICS research paper series, Volume 2, Number 2, March.

Gunaydin H.M., Dogan S.Z. (2004), A neural network approach for early cost estimation of structural systems of buildings. Internaltional journal of project management, 22, 596602

Harding A., Lowe D.J., Emsley M.W., Hickson A., Duff A.R. (1999). Implementation of a neural network model for the comparison of the cost of different procurement routes. Proceedings of the 15 ARCOM annual conference, Liverpool John Moore's University.

Lowe D.J., Hickson A., Harding A., Emsley M., Duff R. (1999). The role of neural networks in early stage cost estimation in the 21 century. Presented to COBRA, University of Salford, Manchester, UK

Makridakis, Wheelwright and McGee (1983). Forecasting methods and applications, John Wiley and Sons.

Proctor C.J., Bowen P.A., Le Roux G.K. and Fielding M.J. (1993). Client and architect satisfaction with building price advice: An empirical stu dy, CIB W55/W95 International symposium on economic evaluation and the built environment, Lisbon, 213-226.

Rafiq M.Y., Bugmann G., Easterbrook D.J. (2001). Neural network design for engineering applications. Comput. Struct, 79, 1541-52

Shtub A. Versano R. (1999). Estimating the cost of steel pipe bending, a comparison between neural networks and regression analysis. Production Economics, 62, 201-7

Soutos M., Lowe D.J. (2003). An investigation into the current practice of elemental cost planning. Proceedings of the first Scotish conference for postgraduate researchers in the built and natural environment (ProBE), Glasgow Caledonia University, 18-19 November.

Soutos M., Lowe D.J. (2004). An Investigation into the implementation of a predictive model for the early stage estimation of elemental building costs, The 3 Scientific Conference on Project Management, Thessaloniki, Greece, 24-35 September.

Trost M.S., Oberlander G.D. (2003). Predicting accuracy of early cost estimates using factor analysis and multivariate regression. Journal of construction engineering and management, 129, 198-204

Seeley I.H (1996). $4^{\text {th }}$ edition, Building economics, Macmillan, London, UK

Smith N.J. (1995). Project cost estimating. Engineering management series, Thomas Telford, London 